\title{
The Theory of Ethiopian Logos: A Semiotics Analysis
}

\author{
JEMAL MOHAMMED \\ Bahir Dar University, Ethiopia
}

\begin{abstract}
Just like a human face, a logo is the principal image of a given institution. This research explored the types of messages Ethiopian public universities want to construct and mediate by the use of logo as well as the definite pattern the logo usage has followed. Both qualitative and quantitative methodologies were employed. By using semiological content analysis, all the available logos of Ethiopian public universities were analyzed. In order to obtain the main philosophical root of the employments of the logos as tools of communication, various in-depth interviews were conducted with communication and public relations directors/experts of eight universities. Peirce's model of semiotics was used as a theoretical frame. The finding of the study discloses that the universities are highly engaged in entertaining dual messages, i.e. modernism vs. traditionalism, through their logos. The leaders of the universities are fascinated in constructing and representing their reality in such a way that modernity is highly required while traditional treasures have obtained special attention. The study discovers that the very essence of a logo is highly misunderstood among the leaders of the public universities of Ethiopia. Furthermore, excessive pictures are used within a logo and many of them are undersized while the imitation of signs is very high (up to $98 \%)$. In short, the universities have failed to construct a strong and distinct visual identity. The researcher draws the theory of the Ethiopian institutional logo (i.e. circle-ness, imitativeness, stuffing, miniaturization, localized-ness, predictableness and symbolic-fixation) that guides the production of visual signs.
\end{abstract}

Keywords: Logo, visual identity, Ethiopia, university, semiotics.

\section{INTRODUCTION}

Visual signs increasingly invade us. Airey describes vividly how the sign system, which normally includes logos, overruns our environment: "Logos bombard us. Think of clothes labels, running shoes, TVs, and computers. From the moment we wake to the moment we sleep, they're an everpresent part of our daily routine" $(2010$, p. 2). The logo is one of the five elements that constitute corporate visual identity [The other four elements are name typography, color and slogan] (Roast, 2006). A logo helps to make a distinction between brands by representing uniqueness and differentiations. It conveys desirable meanings through associations and symbolism. Logos communicate image "cutting through clutter to gain attention, and speeding the recognition of a product or company" (Henderson \& Cote, 1998, p. 15). The rationale is simple: that "pictures are perceived faster than words" (ibid.)

There is not much research in the area of sign systems in Ethiopia, especially by employing semiotics as a method of analysis. Samuel (2006) has conducted a study entitled: Representation of power relations in Ethiopian newspaper front page photographs: A semiotic analysis. He used the government-owned newspaper (The Ethiopian Herald) and two private newspapers (Fortune and The Reporter) as coding objects. The major finding of Samuel's study indicates that the front pages were overwhelmingly dominated by powerful persons who "tended to be portrayed 
positively, sometimes heroic" (p. 5). To the contrary, there was less coverage for ordinary people while they were portrayed as victims rather than as newsmakers.

Ethiopian public universities are attempting to cram too much into the visual containers of their logos, which results in a muddy and cacophonous muddle. This research intends to explore how it is problematic for the educational institutions to construct a strong and distinct visual identity and what the Ethiopian culture and psyche might dictate on the construction of visual identity. Investigating the logos of the Ethiopian public universities can assist in understanding the mediated messages of the signs and the social reality that the universities want to construct while exploring the possible major limitations that need to be improved. "Studying semiotics can assist us to become more aware of the mediating role of signs and of the roles played by ourselves and others in constructing social realities" (Chandler, 2007).

The specific objectives of this study was to 1 ) identify the type of messages the Ethiopian public universities want to construct and mediate by the use of logos; 2) to ascertain the pattern of usage of signs in the public universities' logo system; and 3) to draw a theoretical assumption that can help to understand the construction of logos in Ethiopian public institutions.

\section{LITERATURE REVIEW}

This part of the study will briefly deal with some conceptual backgrounds related to logo design. It has also examined theories of semiotics, which will help to frame the research work.

\section{Construction of Visual Identity: The Place of Logo}

Logo is the principal image of a given company or institution. It is just like a human face. The main visual presentation of an organisation or institution is done by its logo. "[L]ogos act as the primary visual representation of a brand's general image and meaning. As a result, logos can shape the brand's reputation along with consumers' attitudes, their purchase intentions and their brand loyalty" (Whan, Andreas, Pol, Park, 2013, p. 181).

The recognition of a logo is critically important. Customers and clients need to recognise a logo with not much effort or very easily if it has to serve as a corporate visual identity. As Cowin (2008, p. 11) indicates, the recognition of a logo happens at two different levels. "Primarily, viewers must recall having seen the logo at some point in the past (recognition). Secondly, the logo must be linked by association to the proper corporation (recall)".

\section{Semiotics as Theoretical Frame}

Semiotics is the study of signs or the science of signs. It studies "how humans construct meaning for themselves and others, a central concern for communication scholars" (Leeds-Hurwitz, 2009, p. 874). In the study of signs or semiotics there are two models developed by Swiss linguist Ferdinand de Saussure and the American philosopher Charles Sanders Peirce (Chandler, 2007). The Peircean Model is employed here as it is found to be most appropriate for this specific study.

The Peircean Model

Peirce's model consists of three components - the representamen, an interpretant and an object. The representamen is, as Merrell explains, "something that enters into relation with its object, 
the second component of the sign" (Merrell, 2005, p. 28). It is "the form which the sign takes (not necessarily material, though usually interpreted as such) - called by some theorists the 'sign vehicle' (Chandler, 2007, p. 29). On the other hand, an interpretant is close to what would normally been taken as the meaning of the sign. It is the sense made of the sign. The interpretant purpose is relating to and mediating between representamen and the object (Merrell, 2005; Chandler, 2007). The third one is an object. It is what is denoted by the interpretant. The object is "something beyond the sign to which it refers (a referent)" (Chandler, 2007, p. 28).

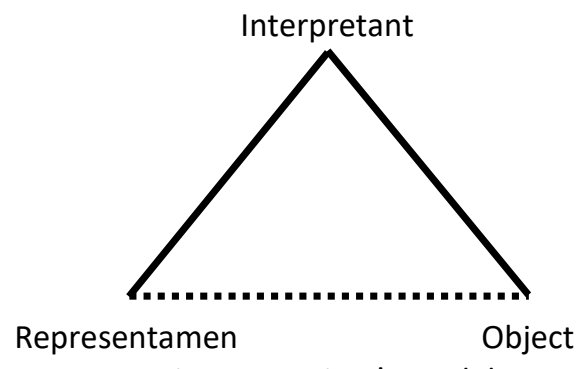

Figure 1: Peirce's model

\section{Typology of Signs}

Though Peirce named more than 66 types of signs, three (icon, index and symbol) are recognised as the most significant (Leeds-Hurwitz, 2009).

\section{a. Icon}

An icon is a sign, which takes some certain qualitative characteristics of its object; thus it has in some way resemblance with its object. The relationship between the object and its referent is not arbitrary. An icon "stands for a referent through some form of replication, simulation, imitation, or resemblance" (Danesi, 2004 p. 26). Danesi mentions onomatopoeia as an example since "sound symbolism is an example of iconicity in language" (ibid.).

Photographs, paintings of natural scene, portrait, a cartoon, a scale-model, and drawings of all kinds (charts, diagrams, etc.) are iconic simply because they are linked to their objects (Chandler, 2007; Danesi, 2004). They are made to resemble or stimulate their referent in some way. As Leeds-Hurwitz notes "An icon has a relationship of similarity; a photograph is an icon because it normally looks like the person or object depicted" (2009, p. 874).

\section{b. Index}

An index is "a mode in which the signifier is not arbitrary but is directly connected in some way (physically or causally) to the signified... - this link can be observed or inferred" (Chandler, 2007, p. 36). Here too the relationship between the object and its referent is not arbitrarily for the reason that, according to Peirce, "The index is physically connected with its object" (cited in Nöth, 1995, p. 113). There is a direct connection between the two, i.e. the object and its referent. "[T]hey (the index and its object) make an organic pair, but the interpreting mind has nothing to do with this connection, except remarking it, after it is established" (cited in Nöth, ibid.). Unlike icons, indexes do not resemble their referents. They simply point out or show where they are - 
as a smoke is an index of fire indicating where the fire is, a cough is an index of a cold and fiver is an index of sickness (Sebeok, 2001).

\section{c. Symbol}

Symbol, unlike icon and index, has a relationship of arbitrariness with its referent. A symbol neither takes any qualitative characteristic of its object, like the iconic sign, nor "physically connected with its object" (Peirce cited in Nöth, 1995, p. 113), like indexical sign. The relationship between the object and its referent "must be agreed upon and learned: e.g. language in general (plus specific languages, alphabetical letters, punctuation marks, words, phrases and sentences), numbers, Morse code, traffic lights, national flags" (Chandler, 2007, p. 36).

In summary, what has been discussed above is vitally important to categorize the data of the research based on the typology of signs so that it would be possible to show whether the Ethiopian educated elite manages to communicate effectively with symbolic signs.

\section{METHODOLOGY}

The research followed both quantitative and qualitative approaches. The quantitative approach helped the study to determine the pattern of the use of sign systems in the Ethiopian universities' logos. To do this, a semiological content analysis of logos has been employed as the data gathering instrument. The total population of the semiological content analysis was all available logos of Ethiopian public universities - 31 in number. Because this study follows complete sampling, the total number of samples for the content analysis is also 31 logos of the universities. Signs, types of shapes, color type, degree of imitativeness and repetitiousness, natural versus manmade and modernism versus 'traditionalism' as well as typology of signs were used as unit of analysis. SPSS was used to check and measure the quantitative data statistically.

The qualitative approach, on the other hand, assisted the researcher to uncover some insights to understand how and why some signs were constructed in the form of logos. The indepth interview was employed as the data gathering instrument and eight universities (Adama Science and Technology, Haramaya, Hawassa, Jimma, Mizan-Tepi, Woldia, Wolkite and Wollo Universities) were purposely selected. The data were gathered from persons who are responsible for the promotion of image of the public universities, i.e. external relation/communication and public relations directors and experts, until a saturation point was reached.

\section{DATA PRESENTATION AND DISCUSSION}

This part of the study presents the research data, discussion and interpretation and the theoretical assumptions that can be drawn about the use of sign systems in the Ethiopian public institutions.

The Content of Ethiopian Public University Logos

\section{a. Signs}

Amazingly, lots of things are incorporated. As the analysis shows, in the total subjects of the study (31 public universities, with 31 logos) around 430 signs or pictures have been used (few signs that are difficult to identify (because they are faded or too small) are not included). This includes gears, opened-books, lighted torches, rays, model of atom, microscopes, graduate caps; natural, 
historical and cultural heritages; bunches of wheat, coffee plants and beans, Enset (false banana); mountains, rivers, waterfalls and lakes. Numerous shapes (circular, arched, semicircular, bended and oval shapes) are also used (see Table 1).

Table 1: Logo signs incorporated in the Ethiopian public universities

\begin{tabular}{lr}
\hline Type of signs & Frequency $\%$ \\
\hline Gear & 93.5 \\
Opened-book & 93.5 \\
Arched/semi circular & 93.5 \\
Circular shapes & 87.1 \\
Vegetation (bunch of wheat/coffee beans, trees...) & 87.1 \\
Historical/cultural heritages & 64.5 \\
Natural heritages & 58.1 \\
Model of atom & 54.8 \\
Rays & 45.2 \\
Lighted torch & 41.9 \\
Mountains & 29 \\
Star /with different forms & 29 \\
Lines & 25.8 \\
Rivers/lakes & 22.6 \\
Microscope & 16.1 \\
Graduate cap & 12.9 \\
The sun & 12.9 \\
\hline
\end{tabular}

The number of signs used by the public universities range from 9 to 22 and the mean is 13.9. It appears that each logo is a tiny picture book. On the top of this, it is hard to find one feature to help the design stand out because lots of signs (with their colors) are stuffed within one logo while they are virtually undersized.

It is extremely important to leave an onlooker or customer with just one thing to remember about the logo (Airey, 2010). Dimarco advises; "your logo will have only a few seconds to be absorbed by the average person".

\section{b. Types of Shapes}

Arched, semi circular and circular shapes have been used by the universities extravagantly (from $87 \%$ to $93 \%$ ). It is unlikely to find a university logo that did not employ at least one of these shapes. This becomes one reason for the logos to lack originality and interest. Even the few universities that tried to follow a new pattern of logo design, such as Debre Birhan, Jimma, Jigjiga and Woldia universities, employ at least one element of the clichéd shapes. Amazingly, the majority of university names (more than 77\%) were written in arched or semicircular form. The Ethiopian public universities' logos are imitative even in utilising shapes (see Table 1).

\section{c. Color Type}

31 of the Ethiopian public universities, within their 31 logos, have used around 200 colour types ranging from 2 to 9 (if colour counting software was applied, we can have more and more number of colours). About $68 \%$ of the universities used 6 to 9 types of different colours while the mean is 6.4. As the universities employed a very high number of signs and colours within one logo, it is very much difficult for viewers to store the logos in memory. 


\section{d. Degree of Imitativeness and Repetitiousness}

Less than $2 \%$ of the public university logo signs can be considered as original. More than $98 \%$ of the signs are imitated either directly (such as pictures of gear, opened-book, lighted torch, etc.), by their shapes (circular, arched, semicircular, bended and oval) or by their type (historical, natural and cultural heritages and vegetation). Equal to the excessive usage of signs inside a logo, repetitiveness of signs is the major problem in the logo design of Ethiopian public universities.

The repetitious degree of the usage of signs within the logos can be divided into three clusters. Pictures that are found in the first cluster (pictures of gear and opened-book; shapes of arch, semicircle and circle; pictures of vegetation) are used at a very high frequency. More than $80 \%$ of the public universities employed them over and over again. Pictures in the second cluster (signs of historical and cultural inheritances, natural heritages, model of atom, rays and lighted torch) are repetitively employed within the ranges of $40 \%$ to $65 \%$. The third cluster has pictures of mountains, stars, the sun, rivers/lakes, microscopes, and graduate cap (from nearly $13 \%$ to 29\%) (see Table 2).

Astonishingly, it is hard to find a university logo that does not imitate (knowingly or not) at least one picture or sign from another university. Addis Ababa University, which is the first university and the first logo designer in the history of the country's higher education, itself, imitates the emblem of gear and opened-book from the logo of the Ministry of Education.

In short, the findings of this study show that Ethiopian public university logos are highly imitative, which leads them to be highly repetitive. They have been designed with little creativity and originality. The monotonous and repetitive use of similar pictures by many of the university's logos in all the three clusters is evident that Ethiopian public universities have failed to construct a strong visual identity by using logo as a medium.

Table 2: Ethiopian public universities' logo pictures in cluster

\begin{tabular}{llr}
\hline Clusters & Type of signs & Frequency \% \\
\hline One & gear & 93.5 \\
& An opened-book & 93.5 \\
& arched/semicircular & 93.5 \\
& circular shapes & 87.1 \\
& Vegetation (bunch of wheat/coffee beans, trees...) & 87.1 \\
Two & historical/cultural heritages & 64.5 \\
& natural heritages & 58.1 \\
& model of atom & 54.8 \\
& rays & 45.2 \\
& a lighted torch & 41.9 \\
& mountains & 29 \\
& Star /with different forms & 29 \\
\cline { 2 - 3 } & lines & 25.8 \\
& rivers/lakes & 22.6 \\
& microscope & 16.1 \\
& graduate cap & 12.9 \\
& The sun & 12.9 \\
\hline
\end{tabular}

\section{e. Natural vs. Manmade}


From the total signs used within 31 public universities of Ethiopia, more than $69 \%$ are pictures of manmade objects while $31 \%$ are natural objects.

The use of pictures of manmade and natural objects shows around three patterns. First, almost all the logos are a combination of the two - natural and manmade objects, except Adama Science and Technology University. Even though the coders were not able to identify any pictures of natural objects, the former director of the university's communication office, when he explains the logo in the interview, mentioned that there is a tree which represents the Oromo Gada system. "The Gada system is a system of generation segments or gada classes that succeeded each other every eight years in assuming political, military, judicial, legislative and ritual responsibilities" (Asmarom, cited in Zelalem, 2012, p. 57). It is the way it was drawn that deters us from spotting it by considering it is just a manmade object. Second, from the natural objects, the lion's share of the pictures was dedicated to vegetation. The pictures of vegetation are highly dominant (87.1\%) throughout the logos. Natural heritages, mountains, rivers and lakes covered $54 \%, 29 \%$, and $22.6 \%$, respectively.

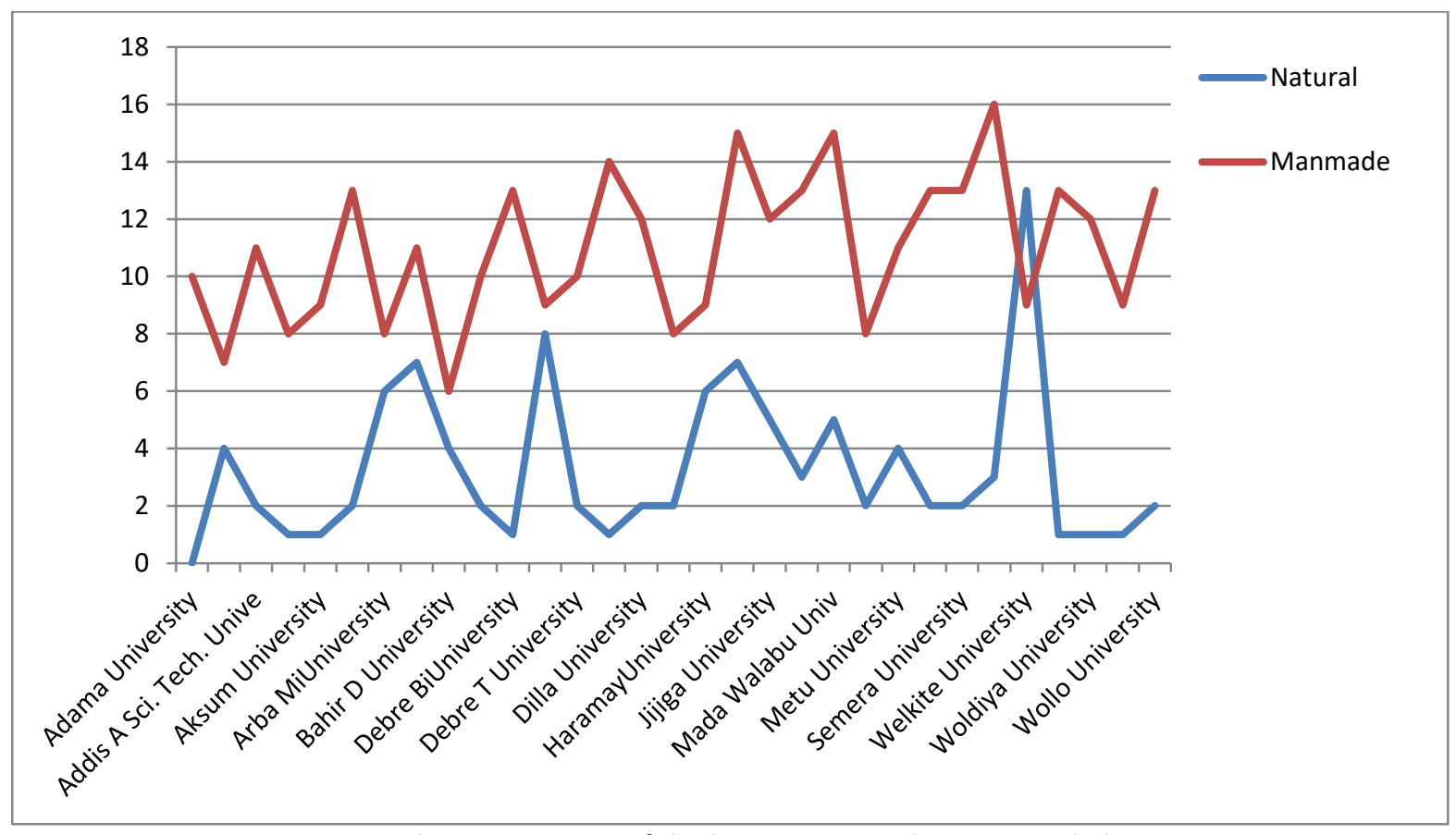

Figure 2: The composition of the logos - manmade vs. natural objects

Third, compared to those who are found in the northern part of the country, much of the universities from the southern part tended to use many more pictures of natural objects. Normally, the southern part of the country has better vegetation. Much of the country's flora and fauna are found here. It is assumed that university officials and the artists, who were responsible for the creation of the logos, were influenced by the environment which surrounds them.

\section{f. Modernism Versus 'Traditionalism'}


Remarkably, the number of gears and opened-book pictures count exactly the same percentage (93.5\% each). The two images appear in Ethiopian public universities logos most repeatedly than any other image. This can be taken as an indicator for the strong ambition the universities have to be the center of science and technology (source of innovation and modernism) that might transform Ethiopia to a developed nation. The picture of an opened-book can symbolise science (which is often based on theory) and the gears can symbolise technology (which is commonly based on practice). They can be considered as emblems of modernity.

On the other hand, pictures of local identity or images of 'traditionalism' (historical, cultural, and natural heritages as well as vegetation) appear from nearly $55 \%$ to $87 \%$ in the public universities of Ethiopia. This is a very good signal that the universities have given significant attention to their local identity in the construction of their logos. Local identity is found to be one of the most important messages that Ethiopian public universities want to construct and mediate through their logo design and production.

Hence, it is clear that these two strongest needs are reflected in the message construction of logos for Ethiopian public universities. The leaders of the universities have a very strong ambition to make their educational institution a center of excellence in science and technology while they are not only in need of promoting their local identity but also proud of it. The availability of the two contrasting, if not conflicting, pictures (modernism versus 'traditionalism') might indicate the competing interests of the universities, or the country in general.

On the other hand, from the availability of excessive numbers (from $55 \%$ to $87 \%$ ) of historical, cultural and natural heritages of the country within the logos of the public universities, it is possible to infer that logos are used to play an ideological role by reflecting the fact that the educated elites are not only proud of their heritage but also ambitious enough to protect and maintain them - "In defining realities signs serve ideological functions" (Chandler, 2007).

But this cannot be used as justification to use an extended number of pictures or images and other symbols as logos. What many of the university officials and artists who designed the logos for the respected universities failed to understand is that the logo is not the right medium to entertain such complex messages. Airey writes, "A solid iconic design is one that onlookers will remember after just one quick glance... Quite often, one quick glance is all the time you get to make an impression" (2010, p. 33). Customers and clients need to recognise a logo with little effort and very easily.

\section{Typology of Signs Employed in the Logos}

Based on Peirce's most significant types of signs (i.e. icon, index and symbol) (Leeds-Hurwitz, 2009), the following is an observation of where the Ethiopian public university logos can be located.

\section{a. Iconic Signs}

As it has been discussed in the review of literature, an icon is a sign which takes some certain qualitative characteristics of its object. In other words, it has in some way resemblance with its object. Thus, the relationship, between the object and its referent, is not arbitrary. 
From the data (Table 1) it is clear that iconic signs are used within many of the logos. This includes pictures of vegetation (87\%), historical/cultural heritages (nearly 65\%), natural heritages $(58 \%)$, mountains (29\%) and rivers/lakes (nearly $23 \%$ ). The pictures are iconic in a sense that they clearly signify their object. That means, for instance, the pictures of Gondar castle, Axum obelisk, wild animals, the coffee plant or bunch of wheat directly refer their objects, i.e. the physical materials. That is what an iconic sign does. Iconic signs are employed in the universities' logos most frequently next to gear and an opened-book pictures (93.5\%, each), which are indexical signs [discussed in the following section].

Besides putting numerous pictures within one logo (the mean average is 12.39), the problem of using these iconic signs as pictures in logos for Ethiopian public universities is the absence of any clear relationship between the iconic signs and the universities. There is no direct connection between the iconic pictures or their referent and the universities. The iconic pictures may be good to signify or represent their localities. They are actually playing an indexical role by referring to their local culture, tradition, history, people, etc. though that may not be the intention of the university. For instance, Axum obelisk and Gondar castle serve to signify the culture, history and people of their respective places.

It is evident that iconic signs have been employed in an erroneous way due to two major factors: 1 ) their creators made a wrong assumption - a certain picture of local identity can signify a government institution (such as a public university) that operates in the locality; and 2) the logos are composed of many pictures of local identities while by their intricate nature they are not the appropriate means of communication to mediate complex ideas and messages.

On the other hand, a university is a social institution, which is found in an abstraction. It is not found as an object that can be seen and touched. Because of this it is unlikely to have an icon that can represent a university and then be used as a logo. This is because an icon "stands for a referent through some form of replication, simulation, imitation, or resemblance" (Danesi, 2004 p. 26).

\section{b. Indexical Signs}

When a sign is indexical, the signifier is directly connected in some way with its object. The relationship between the two, i.e. the signifier and the object, would not be arbitrary (Peirce cited in Nöth, 1995; Chandler, 2007). Standing from this theoretical point of view, the data show that in many of the university logos, there is a direct connection between the referents (logo images) and its object (university).

As reported earlier (Table 1), among all 31 public universities in the country, $93.5 \%$ of them have incorporated pictures of gear and an opened-book within their logos. Gear and an opened-book are the most frequently used pictures in the construction of public university logos in Ethiopia. The model of atom image has also been used as part of the logo by nearly $55 \%$ of the universities.

The three pictures have a connection to higher education in some way as the book may represent education, knowledge and research while the gear can be taken as an indicator for technology and machinery. The model of atom may represent education of natural science. The inclusion of the microscope (16\%) and graduate cap (nearly 13\%) as part of logo pictures within a significant number of universities ( $29 \%$ in total) is also an indicator for the popular use of 
indexical signs in the Ethiopian university logos because the two objects have a direct connection to higher education.

The challenge is that, since these images have been employed by the majority of the universities (from $13 \%$ to $93.5 \%$ ) monotonously, the signs are unlikely to be in a position to construct distinct visual identity for a single Ethiopian university. Their power has already been reduced due to the excessive use. To stand out from the crowd is the main purpose of designing a logo, in other words "Iconic designs that stand apart from the crowd have just one feature to help them stand out..." (Airey, 2010, p. 36).

Of course, the availability of indexical sign within the logos of Ethiopian universities would communicate to an onlooker that the logo belongs to a higher educational institution or university; but not for which university it belongs. The main purpose of a logo is, however, to represent a single organisation's characters, identities and uniqueness, differentiations and serves as brand identity over a period of time.

\section{c. Symbolic Signs}

Unlike the other typology of signs, i.e. icon and index, a symbolic sign has no any relationship with its referent. A symbol neither takes any qualitative characteristic of its object, like the iconic sign, nor is it "physically connected with its object" (Peirce cited in Nöth, 1995, p. 113), like the indexical sign. Due to this, the relationship between the object and its referent need to be learned or agreed upon (Chandler, 2007).

The data depict that four pictures (pictures of ray, lighted torch, star and the sun) have been used as symbolic signs within the logos of the 31 Ethiopian public universities. They are symbolic as long as there is no any logical relationship between knowledge, education and learning and the light that comes out or spreads form these sources of light. The relation is arbitrary, i.e. learned. But again, these images are employed monotonously - the universities' logos used rays, a little more than $45 \%$; a lighted torch, nearly $42 \%$, stars, $29 \%$ and the sun, about $13 \%$.

From all other symbolic signs (rays, stars and the sun), the lighted torch is frequently used in the Ethiopian education system as a logo. It is commonly used by institutions such as rural area elementary schools to higher educational institutions (university and college) in Ethiopia.

Almost all of the symbolic signs that are found in the logos are signs, which have been used for many years if not a century as a referent for knowledge, education and wisdom. The researcher has not found any new symbolic sign used within the logos of the universities, except Debre Birhan and Jigjiga Universities. Debre Birhan University uses a picture of a key to enclose some of its images while Jigjiga University uses a letter mark (see Figure 3).

The problem is that both of the universities failed to limit the use of these symbolic signs, considered as innovative compared to the long-time problem public universities have in relation to logo design. Both symbolic signs have been flooded with more than 9 pictures from inside and outside, which has diluted their strength to stand as a distinct visual identity.

If the two universities, Jigjiga and Debre Birhan, had entirely depended on the two distinct symbolic signs (as shown below as an example in Figure 4), they would have opened a new chapter in the construction of logos for higher educational institutions in Ethiopia. 


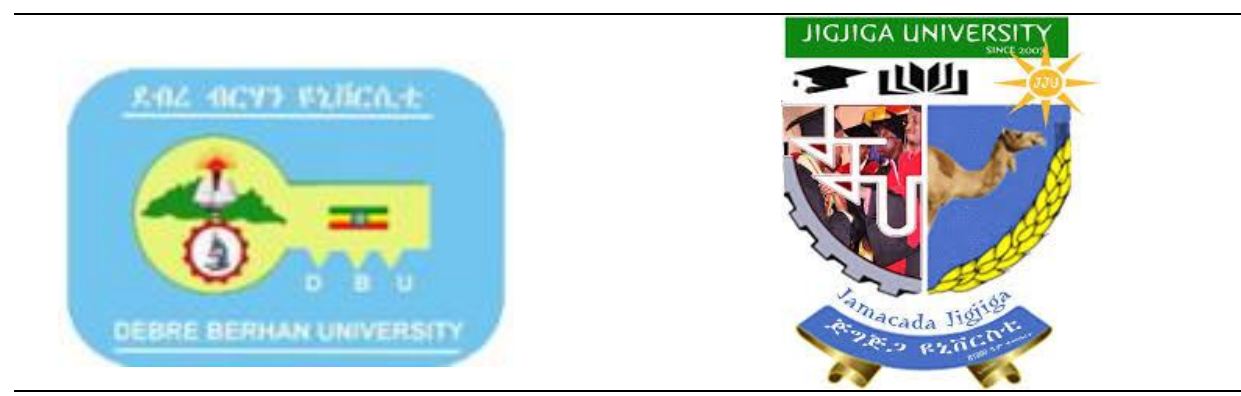

Figure 3: Shows how the two universities tried to use symbolic signs as logo
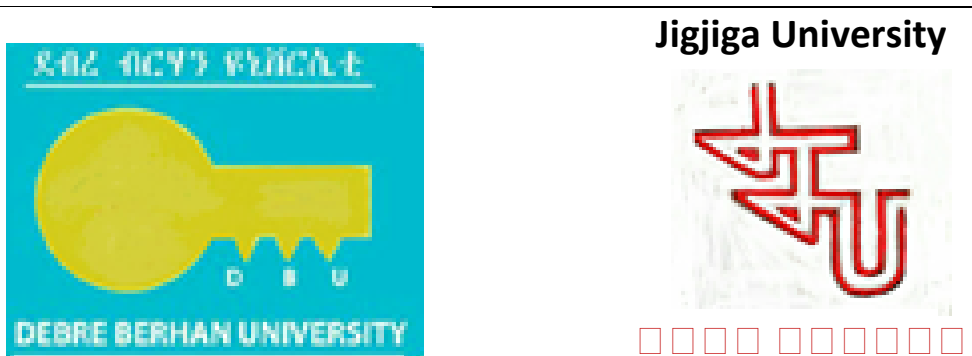

Figure 4: The two universities' logos can be entirely from symbolic signs if they were put like these

There was one more attempt to use a symbolic sign as a logo by Adama University when it had a president from Germany. But before the logo was formally utilised, the president's contract was terminated. The logo was thus annulled before its endorsement. The University Board gave instruction for the designing of the current logo, believing that the university logo had to incorporate and reflect the local culture or identity (LI6) (Figure 5).

\begin{tabular}{|c|c|c|c|c|c|}
\hline Logo & $\begin{array}{l}\text { Type of } \\
\operatorname{sign}(s)\end{array}$ & $\begin{array}{l}\text { Number of } \\
\text { signs/pictures }\end{array}$ & $\begin{array}{l}\text { Number of } \\
\text { colors }\end{array}$ & $\begin{array}{l}\text { Number of imitated } \\
\text { pictures and shapes }\end{array}$ & $\begin{array}{l}\text { Name } \\
\text { writing style }\end{array}$ \\
\hline & $\begin{array}{l}\text { purely } \\
\text { symbolic } \\
\text { (pictorial/ } \\
\text { abstract) }\end{array}$ & $\begin{array}{l}4 \text { (including its } \\
\text { name) }\end{array}$ & Only 2 & There is no & $\begin{array}{l}\text { Very original } \\
\text { (bottom, } \\
\text { horizontal) }\end{array}$ \\
\hline
\end{tabular}




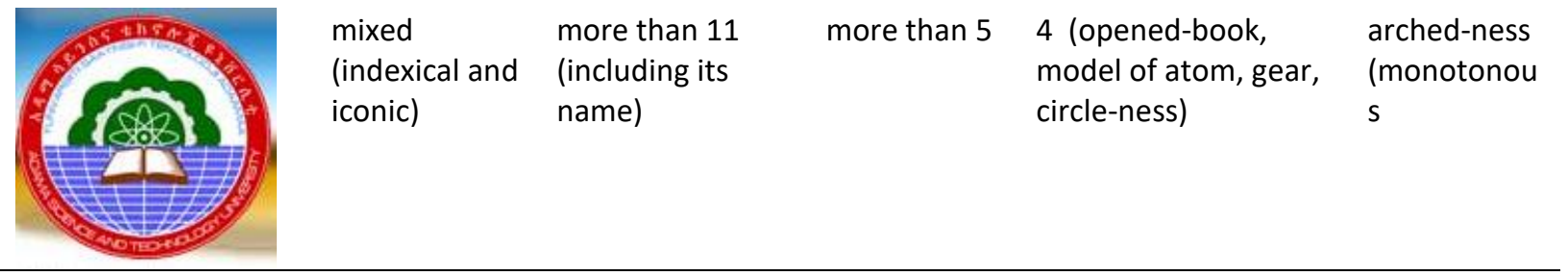

Figure 5: The contrast between the annuled (top) and current (bottom) logo's of Adama University

In summary, often than not the typology of signs (icon, index and symbol) has been used in a very haphazard way within the logo of public universities in Ethiopia. Virtually, there is not one university logo that uses only one typology of the signs. All the university logos have two or all three of the sign types showing that the logos were produced in a hit-or-miss approach. In addition, as it has been stated, the number of signs within each logo is too large while many of the signs are undersized. These all create unnecessary complications, which is not good for a logo that "will have only a few seconds to be absorbed by the average person" (Dimarco, 2017).

One might ask why Ethiopian designers were fond of the round shape for designing logos? Two possible assumptions can be drawn here. The first one is directly related to the formation of logos, i.e. technical influence. As long as logos are constructed from miniaturized pictures, it seems that the circle has been used as a frame to make the logo a single entity. Though this is also possible by using other shapes (such as triangle or rectangle), the designers strictly employ the round shape only. Thus, the question is why? The second assumption is related to cultural influence. The Ethiopians' culture appears to be highly attached to roundness. The huts, where the rural people live, are round. The 'Enjera', the typical food most Ethiopians eat, is round. They often eat the 'Enjera', by forming a round shape. When they do mediation between individuals, still they form a circular shape.

One more question that needs to be addressed here is: What would be the likely influence that operates within the mindset of the designers to cram too many pictures into the visual containers of their logos? It would be a good idea to closely observe the collectivistic culture Ethiopian has, which emphasise on prioritisation of group interest over individual or self. Ethiopians normally eat together, the food served on one big plate; they sit together for coffee ceremony; they sit together to express their condolence; their photo albums have more photos taken in groups (with family members, friends, colleagues, staff members, etc.) than photographs of self. This would most probably sway the designers' mindset.

\section{Theory of the Ethiopian logo}

From the data presented above, some perpetual patterns of logo usage can be identified. Since these logo patterns are incessantly persistent, the researcher prefers to call them syndromes.

\section{a. Circularity}

More than $87 \%$ of the logos of the public universities are made up of circles. Arched and semicircular shapes (which has similar nature with the circle shape) also appeared in $93.5 \%$ of the logos. Only five universities (Addis Ababa Science \& Technology, Debre Birhan, Jigjiga, Jimma and Woldia Universities) used different shapes for their logos. Even here, there is a possibility of 
finding circle or semicircle elements within the logo. Thus circularity is one of the syndromes that hinder the uniqueness of Ethiopian public universities logos and in turn deters the construction of unique visual identity.

In the in-depth interview, the researcher raised this point to one of the interviewees (LI2), who has experience in the arts. He insisted that a circle is used to combine the different pictures within a logo into a single entity. Circles play a unifying role in Ethiopian universities' logos because there are numerous pictures that are used to construct a single logo. If they were excluded, the logo or the pictures would look scattered and un-unified.

It is difficult to conclude this was the only reason in the employment of circles since many of the universities used them twice and some also used three and more circles within a logo.

\section{b. Imitativeness}

This syndrome is about using the same or similar pictures or shapes that have been already used in logos of other universities. Because the majority of public universities logos are highly flooded with similar pictures and shapes (gear, an opened-book and models of atom; arched, semicircular and circular), it is inferred that imitation is operating in a very high scale. The danger is that when imitation occurs, originality dies out. "A distinctive logo is one that can be easily separated from the competition" (Airey, 2010, p. 30). The consequence of imitativeness is that the logos of the universities are highly similar which in turn creates a problem for the higher educational institutions to visually distinguish themselves from one another.

The problem of sameness created by the imitation of signs among Ethiopian university logos was questioned in the interviews. Some of the interviewees remarked:

\footnotetext{
"We were not aware of it" (LI3).

"We need to revise our logo!" (LI7).
}

\section{c. Cramming}

This syndrome stems from incorporating a large number of pictures within one logo. As it has been mentioned earlier, the minimum number of pictures or signs within the public universities is 9 while the maximum number is 22 and the mean is 13.9.

There are two immediate drawbacks caused by cramming syndrome. One, it is difficult for viewers to pick a single picture when they are exposed to a variety of signs that unnecessarily compete for viewers' attention while many of them are undersized. In principle, viewers or customers need to do it with a quick glance. "A solid iconic design is one that onlookers will remember after just one quick glance" (Airey, 2010, p. 33).

The second drawback is related to the absence of one dominant picture - a picture that is singled out and overrides others. Woldia University tries to magnify one sign over the others. But the sign is an opened-book, which has been used by many universities (more than 93\%) - a victim of imitativeness syndrome that leads to repetitiveness.

Many of the interviewees agreed with this proposition - cramming is one of the major problems in creating visual identity for their respective universities. 
We understand that the availability of many pictures is not helping us. It is not helping the memorability of our university. Members of the leadership of the university have agreed up on this point and we [the External Communication and Public Relations Directorate] have obtained their consensus to change the logo (LI4).

But the bad news is that there are other universities that have agreed or decided to add more pictures to their logos:

"Our university recently increased its center of excellences. Because of this at the management level, we are discussing to include some more pictures in the logo that can represent the new areas..." (LI6).

As observed at the time of the interviews, cramming is a critical problem to the extent that some of the interviewees themselves have difficulties in remembering and recalling each picture in the logo instantaneously. Interviewees needed to look at the print version of the logo to recall.

\section{d. Miniaturisation}

This syndrome can be considered as the direct effect of cramming syndrome. The public universities wanted to place as many pictures possible within a logo. This interest forced the designers to cram the pictures within a logo, which normally has limited space. Thus, the automatic result is miniature or undersized pictures or signs. Onlookers neither have preparedness nor give any attention to view logos as they do for viewing TV news or any other mediated message. Logos of Assosa, Haramaya, Metu, snd Debre Briha universities are a good example here (Figure 6).

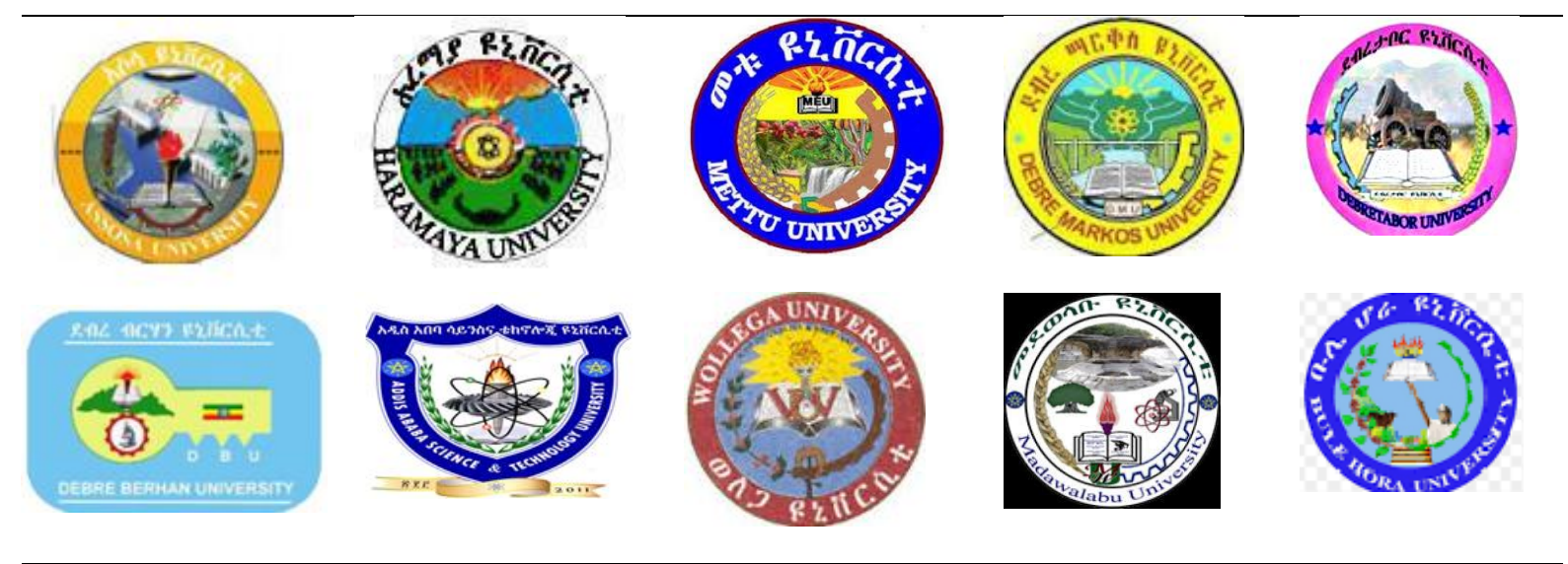

Figure 6: Examples of logos that have miniatured pictures difficult to know what they really are 


\section{e. Inadaptability}

Virtually all the university logos are not versatile to be printed in small sizes as some of the smaller images would either fade or disappear. Thin lines and tiny pictures "are likely to fade or disappear when printing in small sizes" (Dimarco, 2017). As one of the informants in the interview shared his experience, his university had made an agreement with an Indian agency to print the logo of the university on various promotional materials including ties. When the agency delivered the sample materials, the logo did not look good on much of the materials especially on the ties (LI4). They found some of the pictures disappeared, some were deformed and some were looking dim. He said that they asked the agency why this had happened.

"They told us that we cannot do more than this with your logo which has the design with such and such pictures" (LIO4).

Inadaptability can be considered as a direct negative effect of the miniaturisation syndrome.

\section{f. Localisation}

Localisation begins from their name itself since all universities are named after their place of establishment. Of course, this is a general trend around the globe as many universities take their names from their place of establishment. What makes the Ethiopian public universities' names strange is that all (100\%) are called after the name of their place of establishment. Some believe that their naming is politically motivated. Even so, this study has not acquired any data that can support this claim.

The major localisation effort, however, is manifested in incorporating various artifacts and natural heritages that are believed to be typical to that area where the university is established. As almost all of the communication directors and experts of the selected universities, who were interviewed for this study, confirmed to the researcher, the major rationale for the inclusion of pictures of various artifacts and natural heritages that have social, cultural and/or economic relevance to the specific local areas is to employ them as a means of representation (LI1, LI2, LI3, LI4, LI5...).

One of the interviewees (LI2) defends the importance of localising logos:

As long as you take the name of a place and use it as a name for your university, you have a historical responsibility to put a peculiar picture which could depict that specific place. Bahir Dar University cannot avoid Lake Tana. You have institutional responsibility. There's no way for Gondar University to shun the castle of Gondar from its logo as long as it uses as its name. Simplicity is not as such important. How can you have University of Jimma while coffee is not part of its logo?

It is based on such assumption that all universities (nearly 97\%), except Addis Ababa University - the first university in the country - incorporated at least one picture of local artifacts or natural heritage in their logos. 
Because pictures of local artifacts and natural heritage are used in this way - local identity as a gateway - at least two problems occurred: 1 ) there is replication by using the same or similar pictures of artifacts or natural heritage, which normally kills off freshness of the sign by making it monotonous in the eyes of viewers (see Table 3); 2) the representation of the localities is very much feeble since many of the universities employed more than one artifact or natural heritage of the local area. With no doubt the two signs will compete for viewers' attention, which is unnecessary.

On the other hand, the link between the local artifacts or natural heritage and the university is obscure. What is the relationship between the two? If, for instance, Woldia University manages to be a center of excellence in architecture at least in the Amhara region, its use of Lalibela Church will be meaningful. Or if Bahir Dar University is able to be a center of excellence in water engineering at least in the Amhar region, the use of Tana Lake or Nile river will be meaningful.

Table 3: The domination of local artifacts \& natural heritages on the logos

\begin{aligned} \hline Universities (example) & Local artifacts and natural heritages \\ Ambo & Limestone building units \\ Adigrat & Qarhot - a local handwork, used as food-table \\ Wollo & Kirar \& Masimqo (traditional musical instruments) \\ Woldia & Church of Lalibela \\ Wolkite & Cultural huts and grasslands used as networking system \\ Bule Hora, Dilla, Jimma, Mizan \& Wollega & Coffee plant \\ Hawassa, Wachemo, Wolaita \&Wolkite & Enset (false banana) \\ Dilla \& Mizan & coffee and Enset \\ Bahir Dar & River Nile, Lake Tana, Tiss Abbay (the fall of Nile) \\ Axum \& Mekelle & obelisk of Axum \end{aligned}

\section{g. Predictability}

Predictability is mainly the byproduct of the three syndromes discussed above, i.e. imitativeness (that leads to repetitiveness) and localisation syndromes. Sameness of signs in pictures (an opened-book, gear, bunch of wheat...) and shapes (circle-ness, arched-ness...) and the inclusion of local identity as a gateway establish the predictability syndrome of Ethiopian public universities' logos.

\section{h. Symbolic-Fixation}

The public universities have almost a fixed number of symbolic signs (rays, lighted torch, stars, and the sun), which have been used for many years to represent the importance of the spreading out of education, knowledge and wisdom. Because they have been employed monotonously, their power of representation fades out. Therefore, it is clear that the Ethiopian educated elite are not only less literate in communicating with symbolic signs but also they are fixated on the old and boring symbolic signs. It is here symbolic-fixation attains its foundation.

\section{CONCLUSIONS/RECOMMENDATIONS}

One of the main objectives of this research was to point out the type of messages Ethiopian public universities want to construct and mediate by employing various signs through the production of logos. From the analysis of the data, it is clear that the universities' logos are engaged in 
entertaining dual messages, i.e. modernism and traditionalism. They construct and represent their reality in such a way that modernity is highly required while traditional treasures (cultural, historical and natural inheritance) have been paid special attention to play their part for the prosperity of the local people and the country at large.

The problem is that the very nature of logos does not allow the conveyance of such complex messages. It seems that the leaders of Ethiopian universities were not able to realise the essence of the logo. The other major obstruction is the inclusion of abundant pictures within a logo where many of the pictures are undersized. Using similar pictures (imitating one another) and many colours within a logo are also major impediments in the construction of uniqueness and differentiation that have to lead to recognition.

Owing to this, though the logo is intended to be the principal image of a given institution, Ethiopian public universities logos are not serving as strong visual elements within an organisation's overall identity system. They are unlikely to represent uniqueness and differentiations, identification and recognition of the universities. In short, it is hard to claim that public university logos, as semiotic textual entities, are designed to generate an identification, recognition and reputability of a given university.

Due to this, the researcher would like to suggest that almost all of the universities need to revisit their logos and modify or recreate logos that are free from the syndrome of Ethiopian logos which is theorised by this study, i.e. circle-ness, imitativeness, repetitiveness, stuffing, miniaturization, localized-ness, Un-adaptableness, predictableness, and symbolic-fixation.

\section{ACKNOWLEDGMENT}

The author would like to express his thankfulness to Birhanu Kindu, a journalist and artist at Amhara Mass Media Agency, who draws the ideal logos as an example (Figure 4).

BIODATA

Jemal Mohammed is an associate professor at Bahir Dar University, Department of Journalism \& Communications, Ethiopia. Email: jemalmohammed99@gmail.com 


\section{REFERENCES}

Airey, D. (2010). Logo design love: A guide to creating iconic brand identities. USA: New Riders. Bergman, T. (2009). Documentary film theories. In, Encyclopaedia of communication theory. United Kingdom: SAGE Publications.

Chandler, D. (2007). Semiotics: The basics (2nd ed.). NY: Routledge.

Cobley P., \& Jansz, L. (2003). Introduction to semiotics (Ed. Richard Appignanesi). UK: Icon Books Ltd.

Cowin, E. (2008). The evolution of U.S. corporate logos: A semiotic analysis (Thesis Degree, Master of Arts in the Department of Communication, University of Central Florida, Orlando).

Crable, B. (2009). Meaning theories. In S. W. Littlejohn \& K. A. Foss (Eds.), Encyclopaedia of communication theory. UK: SAGE Publications.

Danesi, M. (2004). Messages, signs, and meanings: A basic textbook in semiotics and communication (3rd ed.). Toronto: Canadian Scholars' Press Inc.

DiMarco, P. (2017). 5 principles of good logo design in logo design. Retrieved from https://qubeshub.org/groups/saber/File: Principles_of_logo_design.pdf

Fairhurst, G. (2008). Organizational discourse. In W. Donsbach (Ed.), The international encyclopaedia of communication. Australia: Blackwell Publishing Ltd.

Fitsumbirhan, S. (2006). Representation of power relations in Ethiopian newspaper front page photographs: A semiotic analysis (Unpublished thesis masters, Addis Ababa University).

Henderson, P. W., \& Cote, J. A. (1998). Guidelines for selecting or modifying logos. Journal of Marketing, 62(2), 14-30.

Khan, B. (2008). A visual and linguistic analysis of three advertisements for condoms. Cambodia: Institute of Foreign Languages Royal University of Phnom Penh, Russian Federation Blvd.

Kasahun Kebede. (2015). What has to be done on the Ethiopian higher educational institutes' logos?. Hirmata Newspaper, 1(2).

Kordjazi, Z. (2012). Images matter: A semiological content analysis of gender positioning in contemporary English-learning software applications. Novitas-Royal (Research on Youth and Language), 6(1), 59-80.

Leeds-Hurwitz, W. (2009). Semiotics and semiology. In S. W. Littlejohn \& K. A. Foss (Eds.), Encyclopaedia of communication theory. UK: SAGE Publications.

Lulu, R., Asoro, R, Lee, S., \& Sela, S. (2013). Gestalt principles in destination logos and their influence on people's recognition and intention to visit a country. Online Journal of Communication and Media Technologies, 3(1, January).

Merrell, F. (2005). Charles Sanders Peirce's concept of the sign. In P. Cobley (Ed.), Routledge companion to semiotics and linguistics. London: Routledge.

Ministry of Education (MoE). (2016). Retrieved from www.moe.gov.et/

Nadihezda, S., \& Stephen, R. (2006). Corporate visual identity: The communicational role of the brand name and the logo (Bachelor Thesis, Department of Business Administration and Social Sciences, Lulea University of Technology, Sweden).

Jamani, K. (2011). A semiotic discourse analysis framework: Understanding meaning in science education contexts. In S. C. Hamel (Ed.), Semiotics theory and applications. NY: Nova Science Publishers, Inc.

Nöth, W. (1995). Handbook of semiotics. USA: Indiana University Press. 
Sebeok, T. A. (2001). Signs: An introduction to semiotics (2nd ed.). Toronto: University of Toronto Press.

Sirna, Z. T. (2012). Ethiopia: When the Gadaa democracy rules in a federal state. Bridging indigenous institutions of governance to modern democracy (Thesis master, University of Troms $\varnothing$, Norway). Retrieved from https://munin.uit.no/handle/10037/5080

Steinman, C. (2008). Sign. In W. Donsbach (Ed.), The international encyclopaedia of communication. Australia: Blackwell Publishing Ltd.

Leeds-Hurwitz, W. (2009). Semiotics and semiology. In S. W. Littlejohn \& K. A. Foss, (Eds.), Encyclopaedia of communication theory. UK: SAGE Publications.

Whan, C., Andreas, E., Pol, G., \& Park, W. (2013). The role of brand logos in firm performance. Journal of Business Research, 66, 180-187. 


\section{APPENDIX}
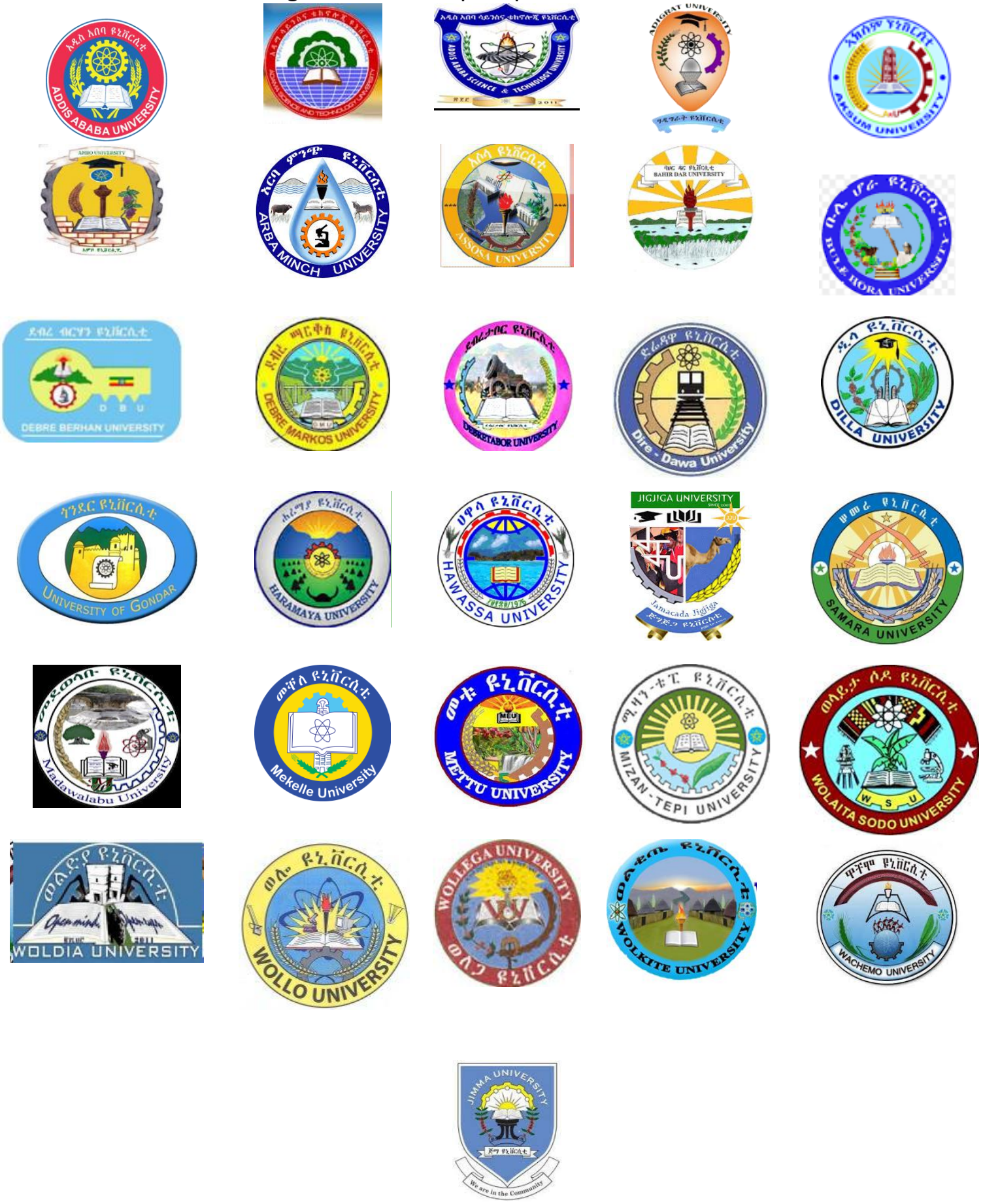